CLINICAL STUDY

\title{
Perchlorate versus other environmental sodium/iodide symporter inhibitors: potential thyroid-related health effects
}

\author{
Bert De Groef $^{1}$, Brigitte R Decallonne, Serge Van der Geyten ${ }^{1}$, Veerle M Darras ${ }^{1}$ and Roger Bouillon \\ Laboratory of Experimental Medicine and Endocrinology (LEGENDO), Faculty of Medicine and ${ }^{1}$ Laboratory of Comparative Endocrinology, Department of \\ Biology, K.U. Leuven, O\&N N9, Herestraat 49, B-3000 Leuven, Belgium \\ (Correspondence should be addressed to R Bouillon; Email: roger.bouillon@med.kuleuven.be)
}

(B De Groef and B R Decallonne contributed equally to this work)

\begin{abstract}
Objective: Perchlorate is a known competitive inhibitor of the sodium/iodide symporter (NIS). Possible thyroid-related effects of environmental perchlorate have created great health concerns, especially in the US, resulting in a debated reference dose (RfD) of $0.0007 \mathrm{mg} / \mathrm{kg}$ per day in drinking water recommended by the National Academy of Sciences (NAS). However, the impact of other environmental NIS inhibitors and the role of iodine seem to have received little attention in the whole debate.

Methods: We performed a PubMed search for articles published up to February 2006, using the key terms perchlorate, nitrate, thiocyanate, iodine, NIS, RfD, thyroid (alone or in combinations), with particular attention for human studies. In parallel, we critically analysed the January 2005 NAS' report, entitled 'Health implications of perchlorate ingestion'.

Results: The relative potencies of prevalent environmental NIS inhibitors (nitrate, thiocyanate and perchlorate) to inhibit iodine uptake have been estimated repeatedly with robust results. Our calculations show that nitrate and thiocyanate, acquired through drinking water or food, account for a much larger proportion of iodine uptake inhibition than perchlorate. Furthermore, the iodine uptake inhibitory effects of nitrate and thiocyanate - as defined by their legally accepted maximal contaminant levels in drinking water - exceed the potential effect of the proposed RfD for perchlorate by far.

Conclusions: Iodine uptake inhibition and any potential downstream effect by perchlorate are highly dependent on the presence of other environmental NIS inhibitors and iodine intake itself. These potential confounders should therefore be considered in future studies and calculations for risk assessment.
\end{abstract}

European Journal of Endocrinology 155 17-25

\section{Introduction}

Since the availability of iodine in the terrestrial environment is limited, the thyroidal follicular cells have adopted a mechanism to concentrate and conserve this important trace element. Accumulation of iodide $\left(\mathrm{I}^{-}\right)$by the thyroid was already known to be an energyrequiring mechanism when its $\mathrm{Na}^{+}$dependence was recognized. In 1996, a sodium/iodide symporter (NIS) was cloned from the human thyroid (1). The expression of the NIS is not confined to the thyroidal follicular cells, as the transporter is also present in lactating mammary glands, salivary glands and gastric mucosa.

The ability of perchlorate to inhibit thyroidal iodine uptake, thereby potentially inducing hypothyroidism, has been recognized since many decades, even resulting in therapeutic applications for hyperthyroidism $(2,3)$. Also the mechanism of action, i.e. competitive inhibition of thyroidal iodine uptake at the level of the NIS, has been elucidated. Based on clinical studies, the perchlorate dose required to cause hypothyroidism in adults is estimated to be more than $0.4 \mathrm{mg} / \mathrm{kg}$ per day for months or longer (4). Because of its potential health effect, exposure to environmental perchlorate has recently generated serious debates in the endocrinological, toxicological and ecological community, and resulted in a series of papers in medical journals and in a report of the National Academy of Sciences (NAS), proposing a reference dose (RfD) (see Table 1 for ecotoxicological terminology) for perchlorate of $0.0007 \mathrm{mg} / \mathrm{kg}$ per day (4), which in turn is subject to criticism.

Studies on perchlorate and possible thyroid-related health effects have paid only little attention to other environmental NIS inhibitors such as nitrate and thiocyanate. However, these anions constitute ubiquitously present goitrogenic anions, for which maximum 
Table 1 US Environmental Protection Agency (EPA) definitions of terminology used in environmental toxicology and regulation (URL source: http://www.epa.gov/NCEA/bmds_training/appendices/glossary.htm).

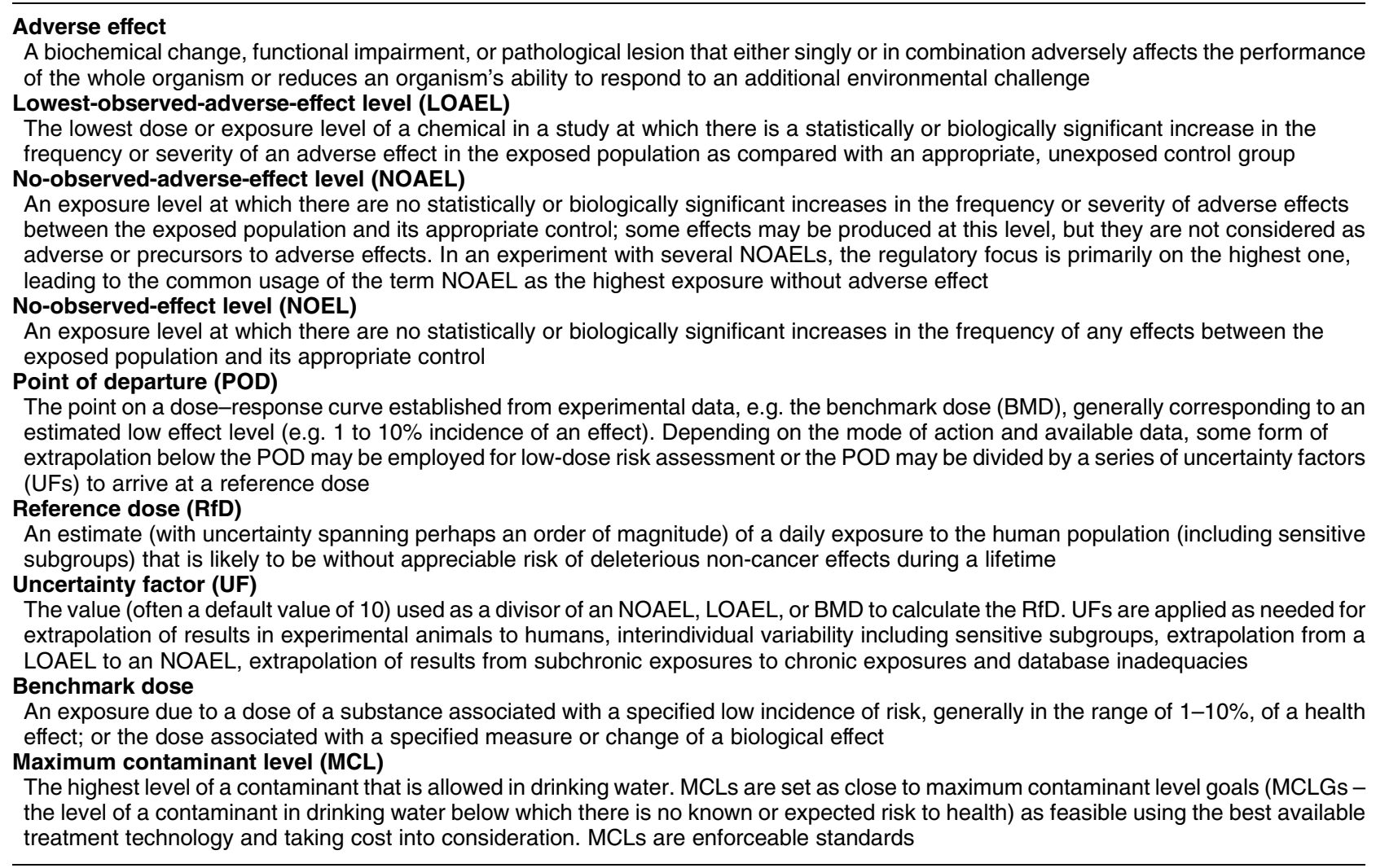

contaminant levels (MCLs) in drinking water have been established. To gain more insight into the large amount of old and recent experimental data and evaluate whether the proposed RfD for perchlorate by the NAS is in line with the presently available scientific evidence, especially with regard to the role of other environmental NIS inhibitors, we performed a literature study along with a critical analysis of the NAS report.

\section{Competitive NIS inhibitors and their relative potencies}

The electrophysiological properties of the NIS have been examined in Xenopus oocytes, Chinese hamster ovary ( $\mathrm{CHO})$ cells, and the cloned rat thyroid cell line FRTL-5 (5-7). A wide variety of monovalent anions with a similar ionic radius, including perchlorate $\left(\mathrm{ClO}_{4}^{-}\right)$, thiocyanate $\left(\mathrm{SCN}^{-}\right)$and nitrate $\left(\mathrm{NO}_{3}^{-}\right)$, were found to generate similar steady-state inward currents as does $\mathrm{I}^{-}$, suggesting that these anions are also transported by the NIS and act as competitive inhibitors for iodine uptake by the thyroid. Whether or not $\mathrm{ClO}_{4}^{-}$is actually transported into the follicular cells by the NIS is still a matter of debate, but using stably transfected COS-7 and FRTL-5 cells, Van Sande et al. provided evidence for such a translocation (8). The relative potencies of $\mathrm{ClO}_{4}^{-}, \mathrm{SCN}^{-}, \mathrm{NO}_{3}^{-}$and $\mathrm{I}^{-}$to inhibit radioactive ${ }^{125} \mathrm{I}^{-}$uptake by the human NIS stably transfected in $\mathrm{CHO}$ cells were recently investigated by Tonacchera et al. (9). These authors showed that the relative potency of $\mathrm{ClO}_{4}^{-}$to inhibit radioactive $\mathrm{I}^{-}$uptake at the NIS is 15,30 and 240 times that of $\mathrm{SCN}^{-}, \mathrm{I}^{-}$, and $\mathrm{NO}_{3}^{-}$respectively on a molar concentration basis. As shown in Table 2, these data are in agreement with earlier studies in rats (10-12). Importantly, the data of Tonacchera et al. indicate a mode of action by these anions of simple competitive interaction with no evidence of synergism or antagonism (9). Consequently, the $\mathrm{I}^{-}$uptake inhibitory effect of a mixture of NIS inhibitors can be expressed as a perchlorate equivalent concentration (PEC), defined as the sum of the molar concentrations of each individual inhibitor, multiplied by the inhibition potency relative to $\mathrm{ClO}_{4}^{-}(7)$ :

$\mathrm{PEC}=\left[\mathrm{ClO}_{4}^{-}\right]+\left[\mathrm{SCN}^{-}\right] / 15+\left[\mathrm{I}^{-}\right] / 30+\left[\mathrm{NO}_{3}^{-}\right] / 240$.

The concentration of a NIS inhibitor expressed as PEC can be interpreted as the concentration of perchlorate needed to inhibit NIS ${ }^{-}$uptake to the same extent as the given concentration of NIS inhibitor. 
Table 2 Molar concentration-based potencies of thiocyanate and nitrate to inhibit NIS function relative to perchlorate as determined in different studies.

\begin{tabular}{|c|c|c|c|}
\hline Study (Refs.) & Perchlorate & Thiocyanate & Nitrate \\
\hline $\begin{array}{l}\text { Inhibition of radioactive }{ }^{125} \mathrm{I}^{-} \text {uptake by human NIS expressed by } \\
\mathrm{CHO} \text { cells ( } 9 \text { ) }\end{array}$ & 1 & 15 & 240 \\
\hline In vivo inhibition of radioactive ${ }^{125} \mathrm{I}^{-}$uptake in rat (10) & 1 & 10 & 300 \\
\hline In vivo $50 \%$ thyroid weight increase in rats (11) & 1 & 20 & 550 \\
\hline In vitro uptake of radiolabelled $\mathrm{I}^{-}$in rat thyroid slices (11) & 1 & 20 & 400 \\
\hline In vitro uptake of radiolabelled $\mathrm{I}^{-}$in isolated rat thyroids (12) & 1 & 20 & 240 \\
\hline
\end{tabular}

\section{Environmental perchlorate}

Partially due to improved detection methods (ion chromatography and tandem mass spectrometry) (13), low concentrations of perchlorate have been detected in surface- and ground-water in various regions of the US. Perchlorate is used as an oxidant in solid propellants for rockets, missiles, fireworks and certain munitions, but some of the contamination probably has a 'natural' origin $(4,14)$. Following press reports on the contamination of drinking-water wells and especially of breast milk, research programs have been developed to assess the risk from these exposures. In January 2005, the NAS recommended a perchlorate RfD of $0.0007 \mathrm{mg} / \mathrm{kg}$ per day (4), mainly based on a study by Greer et al., the only published prospective study in which multiple doses of perchlorate were given to human subjects (14). In this study, 37 adults were given different doses of perchlorate in drinking water for 14 days, and 8- and 24-h measurements of radioactive $\mathrm{I}^{-}$uptake before exposure, on exposure days 2 and 14, and 15 days post-exposure were performed. The researchers determined $7 \mu \mathrm{g} / \mathrm{kg}$ per day as the no-observed-effect level (NOEL), for this was the dose producing no statistically significant inhibition of radioactive $\mathrm{I}^{-}$uptake (Fig. 1). From regression relationships for 8 - and 24-h relative uptakes on exposure day 14, the true no-effect level was estimated to be 5.2 and $6.4 \mu \mathrm{g} / \mathrm{kg}$ per day respectively ( $0 \%$ inhibition of $\mathrm{I}^{-}$uptake) (14). Dose-response relations from other human studies are in agreement with the Greer et al. study (14-17). Furthermore, benchmark dose (BMD) calculations from occupational studies $(16,17)$ were within the range of the Greer et al. study, and in agreement with the no-observed-adverseeffect level (NOAEL), as judged by hypothyroidism, of $0.4 \mathrm{mg} / \mathrm{kg}$ per day (18). Taking into account the NOEL determined by Greer et al. and a total uncertainty factor (UF) of 10, an intraspecies factor to protect the most sensitive population, the NAS recommends an RfD of $0.0007 \mathrm{mg} / \mathrm{kg}$ per day, which is equivalent to a $24.5-$ p.p.b. concentration of perchlorate in drinking water

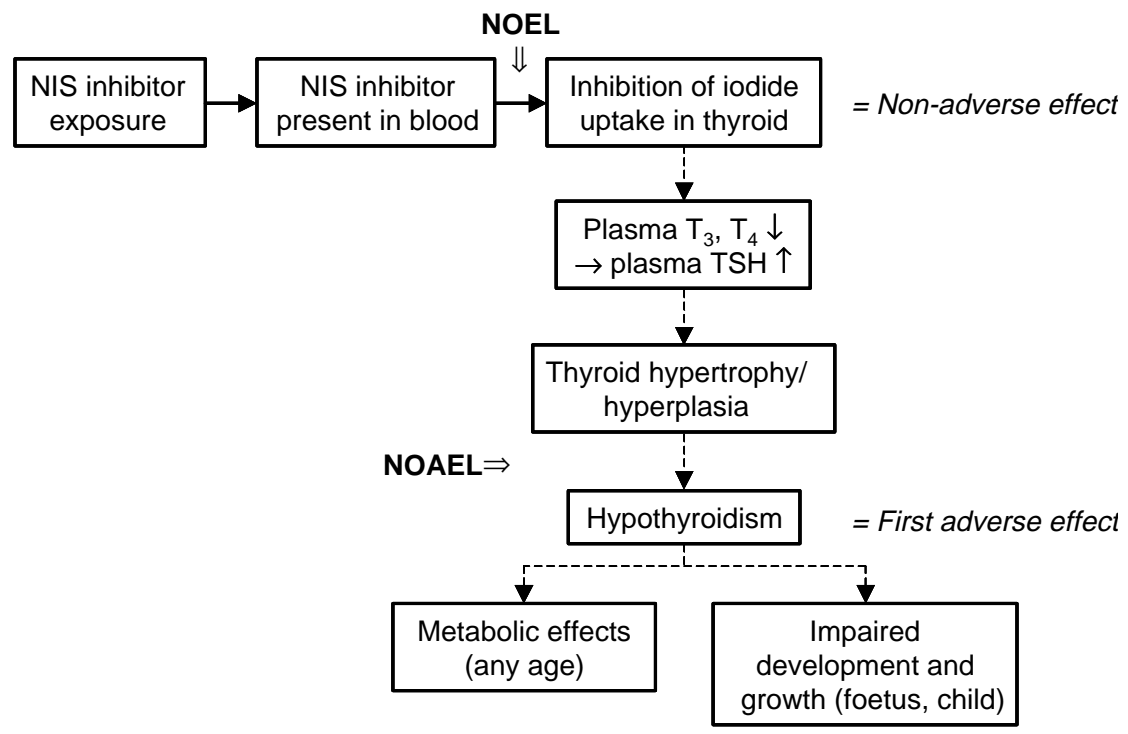

Figure 1 Model for the mode-of-action of NIS inhibitor toxicity in humans, based on the model of the Committee to Assess the Health Implications of Perchlorate Ingestion, which prepared the January 2005 NAS report 'Health implications of perchlorate ingestion'. Dashed arrows represent effects not clearly demonstrated in humans exposed to perchlorate, but biologically plausible in absence of adequate compensation. Hypothyroidism is considered by the NAS as the first adverse effect; inhibition of thyroidal iodide uptake is, therefore, a nonadverse effect. NIS, $\mathrm{Na}^{+} / I^{-}$symporter; NOAEL, no-observed-adverse-effect level; NOEL, no-observed-effect level; TSH, thyroidstimulating hormone (thyrotrophin). 
when assuming a body weight of $70 \mathrm{~kg}$, a daily consumption of $2 \mathrm{l}$ drinking water and the drinking water to be the only dietary source of perchlorate. This RfD was adopted by the US Environmental Protection Agency (EPA) in February 2005, although so far no MCLs for drinking water have been established (URL source: http://www.epa.gov/fedfac/documents/perchlorate.htm). Despite a suggested MCL of 24.5 p.p.b. based on the NAS report, some states have proposed even lower public health goals for perchlorate (e.g. California, 6 p.p.b.; Massachusetts, 1 p.p.b.).

\section{Analysis of the proposed perchlorate reference dose}

\section{NOEL as point of departure}

Determining its RfD, the NAS used an NOEL $(0.0007 \mathrm{mg} / \mathrm{kg}$ per day) rather than an NOAEL $(0.4 \mathrm{mg} / \mathrm{kg}$ per day), which serves traditionally as the point of departure (POD) for risk assessment (4). The NAS concludes that, given their mode of action model (Fig. 1), "the first adverse effect in the continuum would be hypothyroidism. Any effects that follow and result from hypothyroidism clearly would be adverse", and elsewhere; "For adverse health effects to occur in healthy adults, thyroid hormone production must fall substantially and, more importantly, must remain low for at least several weeks". The NAS argues that using a non-adverse effect (thyroidal $\mathrm{I}^{-}$uptake) instead of an adverse effect (hypothyroidism) as the POD is a "conservative, health-protective approach", since inhibition of $\mathrm{I}^{-}$uptake constitutes a biological effect and not necessarily a health effect. This recommendation is probably also based on the fact that only a limited number of studies had been performed on the most sensitive populations to iodine deficiency, being foetuses, neonates and pregnant women. The most feared complication of insufficient supply of thyroid hormones (tri-iodothyronine $\left(\mathrm{T}_{3}\right)$ ) to the developing brain consists of neurointellectual deficit (reviewed in Ref. 19). Though congenital hypothyroidism is not necessarily associated with impaired intellectual development (20), intellectual deficit was shown in the offspring of mothers with overt or even subclinical hypothyroidism $(21,22)$. A relation with attention deficit and hyperactivity disorders has also been suggested (23). Thyroid hormone (in particular $\mathrm{T}_{3}$ ) bound to nuclear thyroid hormone receptors regulates the expression of specific genes in different brain regions following a precise developmental schedule. Foetal thyroid hormone secretion starts only around mid-gestation, underlining the importance of maternal thyroid hormones during the first trimester (24). This also implies that brain damage in regions of iodine deficiency is much more severe than brain damage caused by sporadic congenital hypothyroidism. The hypersensitivity of neonates to the effects of iodine deficiency is explained by their small intrathyroidal iodine pool, which requires increased thyrotrophin (TSH) stimulation and a fast turnover rate in order to maintain normal secretion of thyroid hormones. Hypothyroidism occurring around birth, even transient, can affect brain development and intellectual potential. However, when neonatal hypothyroidism is rapidly diagnosed and appropriately treated, later childhood intelligence is normal (25).

Although the majority of studies in newborns and children show no effects of perchlorate intake on thyroidal function (i.e. unaltered thyroid hormone and TSH levels) or neurodevelopmental state (26-28), these data are incomplete and subject to criticism, often because of the lack of measurement of perchlorate or iodine intake $(25,29)$. An interesting epidemiological study on thyroid function in school-age children born in an area in Chile, where perchlorate is naturally present in drinking water (100-120 p.p.b.) showed that there was no difference in TSH, free thyroxine $\left(\mathrm{T}_{4}\right)$ or goitre prevalence compared to children of two other regions with low (5-7 p.p.b.) or no (<4 p.p.b.) perchlorate in the water (30). Moreover, no elevated TSH levels were observed in neonates of the same regions. Considering thyroid hormone change in the pregnant women of this study as the critical effect (POD) would result in an estimated NOAEL-based RfD for perchlorate of $0.002 \mathrm{mg} / \mathrm{kg}$ per day; the POD was a no-observedadverse level of $0.006 \mathrm{mg} / \mathrm{kg}$ per day and an UF of 3 was applied, owing to the sufficient amount of available data (31). However, the method used by these authors, calculating the RfD by so-called 'benchmarking', remains subject to criticism. Moreover, the use of the Chilean study as a basis of an NOAEL-based RfD has been questioned due to the very high iodine intake of the subjects, which could render substantial competition with perchlorate undetectable. In a following, recently published epidemiological study (32), the effects of chronic perchlorate exposure through drinking water on thyroid function have been studied in pregnant women and neonates in the same areas in Chile, but this time, total iodine intake of the women was similar to that of US pregnant women. Even in the area with the highest dose of perchlorate in the drinking water $(114 \mu \mathrm{g} / \mathrm{l}$, equivalent to an uptake of $93.5 \mu \mathrm{g} /$ day), no effects were found on the serum concentrations of TSH, thyroglobulin or $\mathrm{T}_{4}$, neither in the pregnant women nor in the neonates. Moreover, neonatal birth weight, length and head circumference were consistent with the US standards. This is the first human study indicating that exposure to environmental perchlorate exceeding the NAS' RfD several-fold from preconception until neonatal age interferes neither with neonatal thyroid function nor with neurodevelopment. However, to further exclude any effect on brain development, a follow-up study of these neonates is needed with specific psychoneurological endpoints. As long as our knowledge of perchlorate effects in sensitive 
populations is only fragmentary and toxicological studies with specific neurodevelopmental endpoints are lacking, the NAS' decision to choose an NOEL rather than an NOAEL as a POD for the risk assessment seems to be justifiable.

Of more concern is whether the NAS' tenfold UF is still needed for interindividual variability. Some authors, like Ginsberg and Rice (33), have proposed even higher UFs, but the recent studies of Braverman et al. (17) and Téllez and colleagues (32) contradict this. Ginsberg and Rice argue that an additional UF of 3-10 is needed to account for the potential for greater toxicity to newborns from lactational exposure and for the uncertain relationship between short-term and chronic perchlorate toxicity (33). Braverman et al. showed that in workers of a perchlorate production plant, long-term, intermittent, high exposure to perchlorate did not affect plasma TSH and thyroglobulin levels or thyroid volume. These results suggest that, as predicted by the NAS committee, the inhibition of $\mathrm{I}^{-}$uptake is duration-dependent, and compensatory mechanisms exist to counteract the perchlorate-induced NIS inhibition. Concerning the lactational transfer of perchlorate and the inhibition of $\mathrm{I}^{-}$uptake by the mammary glands as mentioned earlier, Téllez et al. found no perchlorate-induced thyroid effects in neither the Chilean pregnant women nor the neonates exposed to the highest concentration of perchlorate in the drinking water, and moreover, they did not find a decrease in breast milk iodine as feared by Ginsberg and Rice. According to Hershman (34), the vulnerability of pregnant women is far less than would be accounted for by a factor of 2 . Moreover, when already 'playing safe' by determining an NOEL instead of an NOAEL as a POD for risk assessment, an UF of 10 might be greatly overstating human health risks from perchlorate.

\section{Impact of other environmental NIS competitors: nitrate and thiocyanate}

In the whole debate about perchlorate-induced NIS Iuptake inhibition, other NIS competitors have been largely ignored. Nevertheless, nitrate is ubiquitous in food, occurring naturally (as in green leafy vegetables), added as a preservative (in meat and fish) or as a contaminant resulting from organic and mineral fertilizers. For instance, winter iceberg lettuce samples purchased in Santa Cruz County, CA, in 1998, contained an average of $973 \mathrm{mg}$ nitrate per $\mathrm{kg}$ fresh weight (35). Nitrate is also common in surface and ground sources of drinking water, primarily due to the agricultural use of nitrogen-containing organic and mineral fertilizers. A Slovak study has shown that school children living in a community with drinkingwater wells containing high nitrate levels $(>50 \mathrm{mg} / \mathrm{l}$ and some even $>100 \mathrm{mg} / \mathrm{l}$ ) have larger thyroid glands and show signs of subclinical thyroid disorder (thyroid hypoechogenicity by ultrasound, increased TSH levels, positive thyroperoxidase antibodies) with an increased frequency (36). No iodine deficiency was observed in humans exposed to nitrate in drinking water, but hypertrophy of the thyroid gland was noted at nitrate levels exceeding $50 \mathrm{mg} / \mathrm{l}$ (37). Long-term exposure to high perchlorate levels on the other hand, did not cause goitre or hypothyroidism in adults (17).

Furthermore, the presence of dietary thiocyanate should be taken into account. Thiocyanate is a goitrogen interfering in two different steps of thyroid hormone synthesis; it inhibits both thyroidal $\mathrm{I}^{-}$uptake by the NIS, as well as - in higher concentrations - the thyroid peroxidase-catalysed organification of iodine, prior to the iodination of tyrosyl groups of thyroglobulin. Certain cyanogenic glucosides (found in cassava, sweet potatoes, corn, apricots, cherries and almonds) are hydrolysed by glucosidases in the gut and release free cyanide that is converted to thiocyanate. Thioglucosides found in certain plants, especially plants belonging to the Brassicaceae family (cabbage, Brussels sprouts, cauliflower and broccoli), are metabolized within the body to thiocyanates and isothiocyanates. For example, thiocyanate in raw cauliflower can be as high as 9 million p.p.b. and 250000 p.p.b. when cooked (38). Endemic cretinism in regions of Central Africa, where cassava represents a major food staple, has been associated with thiocyanate overload and aggravation of iodine deficiency resulting in foetal hypothyroidism (39). Interestingly, goitres were reported to develop when the critical urinary $\mathrm{I}^{-} / \mathrm{SCN}^{-}$ratio decreases below $3 \mu \mathrm{g} \mathrm{I}^{-}$per $\mathrm{mg}$ thiocyanate, but the goitrogenic effect of cassava is completely reversed by adequate iodine supplementation (40). A very recent epidemiologic study in Germany confirmed the relevance of thiocyanate levels with respect to goitre prevalence, and also demonstrated that a urinary $\mathrm{I}^{-} / \mathrm{SCN}^{-}$ratio was more predictive than urinary $\mathrm{I}^{-}$secretion alone (41). Also cigarette smoking is an important source of thiocyanate in the body. In the US, the breast milk thiocyanate concentrations of smokers were fourfold higher than those of non-smokers (42). Laurberg and colleagues also demonstrated in a recent study that iodine content in breast milk of smoking mothers was twofold reduced (43), most probably due to the competitive inhibition for NIS in the mammary gland. Téllez et al., however, did not find a decrease in the breast milk iodine concentrations of women living in a Chilean area with high perchlorate levels in drinking water (32), a finding that was very recently confirmed in lactating cows receiving high doses of perchlorate (44), suggesting that the effect of perchlorate at these levels is negligible compared to that of thiocyanate from cigarette smoking or cassava consumption.

Thus, nitrate and thiocyanate are both important dietary anti-thyroid agents acting at the level of the NIS. In the Greer et al. study (14), however, data on nitrate and thiocyanate measurements - which might highly vary due to the kind of recently ingested food - were lacking, but could importantly influence iodine uptake 
results. Bruce et al. (38) point out correctly that not all the thiocyanate or nitrate in ingested food is bioavailable and refer to studies showing that about $50 \%$ thiocyanate and $90-100 \%$ nitrate in vegetables is bioavailable following consumption. Furthermore, cooking has also been shown to reduce both thiocyanate and nitrate content of ingested vegetables (38). On the other hand, one should also take into account the half-lives of the $\mathrm{I}^{-}$uptake inhibitors. Thiocyanate, having a half-life of approximately 6 days as compared to 8 and $5 \mathrm{~h}$ for perchlorate and nitrate respectively, remains in the serum 18-29 times longer than the other anions. Based on these differences in half-lives, the perchlorate equivalency ratios of thiocyanate and nitrate in terms of ingested-weight basis have been recalculated to be 0.5 and 240 respectively (9).

The EPA-imposed drinking water MCL for nitrate is $10 \mathrm{mg}$ nitrogen/l or $45 \mathrm{mg} \mathrm{NO}-/ \mathrm{l}$ based on the risk of infant methaemoglobinaemia. The MCL for cyanide is $0.2 \mathrm{mg} / \mathrm{l}$; this criterion is based on the US Public Health Service drinking water standards of 1962 for the protection of human health from the toxic properties of cyanide in drinking water. (High-dose of cyanide inhibits cellular enzymes resulting in histotoxic hypoxia. The central nervous system effects include demyelinating lesions of the brain and a Parkinson-like encephalopathy. The heart is also sensitive to cyanide-induced hypoxia.) Using the perchlorate equivalent ratios of Tonacchera et al. (1:15:240 or 1:8.8:150 for $\mathrm{ClO}_{4}^{-}: \mathrm{SCN}^{-}: \mathrm{NO}_{3}^{-}$on the molar- and weight-based ratios respectively, ref. 9), the MCL of nitrate would have the same effect at the level of the NIS as 300 p.p.b. perchlorate, whereas the MCL of thiocyanate is equal to 22.7 p.p.b. perchlorate (Table 3). In other words, the concentration of nitrate allowed in drinking water would cause an $\mathrm{I}^{-}$uptake inhibitory effect that is 12 times greater than that of perchlorate. For comparison, the Belgian MCLs for nitrate and cyanide are $50 \mathrm{mg} / \mathrm{l}$ (equivalent to 333 p.p.b. perchlorate) and $50 \mu \mathrm{g} / \mathrm{l}$ (equivalent to 5.7 p.p.b. perchlorate) respectively, but actually measured concentrations in drinking water in Belgium are $12.3 \mathrm{mg} \mathrm{NO}_{3}^{-} / \mathrm{l}$ (equivalent to 82 p.p.b. perchlorate) and $<2 \mu \mathrm{g} \mathrm{CN} \mathrm{CN}^{-} / \mathrm{l}$ (equivalent to $<0.23$ p.p.b. perchlorate) respectively (URL source: http://www.aww.be/ inhoud/waterkwaliteit/watersamenstelling.index.htm). Without any perchlorate in it, this water would cause
NIS I${ }^{-}$uptake inhibition that is 3 times greater than the effect of the proposed maximum perchlorate dose of 24.5 p.p.b. An average adult drinking $2 \mathrm{l}$ of this water per day, if it contained the maximum perchlorate dose of 24.5 p.p.b. (which is not the case), would be exposed to a PEC of 164 p.p.b. $\left(\mathrm{NO}_{3}^{-}\right)+0.46$ p.p.b. $\left(\mathrm{SCN}^{-}\right)+$ 49 p.p.b. $\left(\mathrm{ClO}_{4}^{-}\right)=213.5$ p.p.b. PEC, of which $23 \%$ is derived directly from perchlorate, meaning that about $77 \%$ of the resulting NIS inhibition would be caused by the nitrates in the water. The actual average perchlorate level in contaminated active drinking-water sources in California is 8.77 p.p.b. (source: Environmental Working Group analysis of California Department of Health Services drinking water quality database from June 2002), reducing the share of perchlorate in NIS inhibition by drinking water even further to $<10 \%$ (when assuming the same nitrate content).

Taken together, these data indicate that (i) the thyrotoxic potential of perchlorate cannot be seen separately from the effects of other NIS inhibitors such as nitrate and thiocyanate, (ii) when considering the potential thyroid-related health risks posed by monovalent anions, perchlorate only accounts for a small portion $(<10 \%)$ of the exposure from drinking water and (iii) MCLs (recommended for perchlorate, legal for nitrate and thiocyanate) for different NIS inhibitors are largely discrepant.

As mentioned before, in addition to drinking water, food also contains considerable amounts of nitrate and thiocyanate. Using milk and lettuce as examples, it becomes evident that the contamination of monovalent anions in food expressed as PECs is much higher than what is actually present in the contaminated drinking water sources. As shown in Table 4, food contamination is predominantly due to the high levels of nitrate and thiocyanate that would account for 98.83 and $99.98 \%$ of the total NIS I- ${ }^{-}$uptake inhibition caused by milk and lettuce respectively. These numbers hardly change when a $50 \%$ absorption of thiocyanate in the gut is taken into account; 97.84 and $99.97 \%$ for milk and lettuce respectively. Eating just $50 \mathrm{~g}$ lettuce would cause an $\mathrm{I}^{-}$uptake inhibition exceeding the effect of the maximum allowed concentration of 24.5 p.p.b. perchlorate in drinking water by 140 times. By drinking just $100 \mathrm{ml}$ milk, an average 70-kg adult has already been exposed to an equivalent of the perchlorate RfD.

Table 3 MCLs for nitrate and thiocyanate in US drinking water, in comparison to the reference dose (RfD) for perchlorate (weight-based concentrations).

\begin{tabular}{lccc}
\hline & MCL* or RfD $\dagger(\mathrm{mg} / \mathrm{l})$ & $\mathbf{M C L}$ or RfD (p.p.b.) & $\begin{array}{c}\text { Perchlorate dose (p.p.b.) needed to mimic the } \mathbf{I}^{-} \\
\text {uptake inhibition by the MCLs } \neq\end{array}$ \\
\hline Nitrate & 45 & 45000 & 300 \\
Thiocyanate & 0.2 & 200 & 22.7 \\
Perchlorate & 0.0245 & 24.5 & 24.5 \\
\hline
\end{tabular}

*Data from EPA, URL: http://www.epa.gov/safewater/mcl.html\#mcls.

†EPA-adopted RfD for perchlorate.

$\ddagger$ Ratios according to Tonnachera et al. (9). 
Table 4 Indicative nitrate, thiocyanate and perchlorate levels in milk and green leaf lettuce. Nitrate and thiocyanate data are taken from Bruce et al. (38), perchlorate data are taken from the US Food and Drug Administration (URL source: http://www.cfsan.fda.gov/ dms/ clo4data.html).

\begin{tabular}{|c|c|c|c|c|}
\hline & \multicolumn{2}{|r|}{ Milk } & \multicolumn{2}{|r|}{ Lettuce } \\
\hline & $\begin{array}{l}\text { Concentration } \\
\text { (p.p.b.) }\end{array}$ & $\begin{array}{l}\text { Perchlorate dose (p.p.b.) needed to mimic } \\
\text { the } \mathrm{I}^{-} \text {uptake inhibition }\end{array}$ & $\begin{array}{l}\text { Concentration } \\
\text { (p.p.b.) }\end{array}$ & $\begin{array}{l}\text { Perchlorate dose (p.p.b.) needed to mimic } \\
\text { the } \mathrm{I}^{-} \text {uptake inhibition }\end{array}$ \\
\hline Nitrate & 5000 & 33.33 & 1000000 & 6666 \\
\hline Thiocyanate & 4000 & 454.55 & 545000 & 61932 \\
\hline Perchlorate & 5.76 & 5.76 & 10.7 & 10.7 \\
\hline
\end{tabular}

Nevertheless, these levels of nitrate and thiocyanate are considered to pose no health threats and fall well below the legally imposed maximum levels $(45,46)$.

The actual average daily intake of an adult on a US Department of Agriculture-recommended diet is calculated at $33 \mathrm{mg} /$ day perchlorate equivalents of nitrate (244 mg/day) and thiocyanate (277 mg/day) combined (38). The EPA-adopted RfD for perchlorate in drinking water (24.5 p.p.b.) corresponds to an uptake of $0.049 \mathrm{mg}$ perchlorate per day for a $70-\mathrm{kg}$ adult. These data clearly indicate that the daily PEC intake based on nitrate and thiocyanate alone is about 670 times higher than the amount allowed for perchlorate using the NAS/EPA-proposed RfD. A recent study of Sanchez et al. in the Lower Colorado River region confirmed that perchlorate contributes to less than $1-2 \%$ of the PEC for consumption of lettuce, thereby showing that the relative iodine uptake inhibition potential due to lettuce nitrate was 2 orders of magnitude higher than that due to the trace levels of lettuce perchlorate (47). Considering all these data, it is obvious that either the RfD for perchlorate is unrealistically strict, or the MCLs for nitrate and thiocyanate are far too high and should be revised accordingly. The latter is hardly possible, as the natural nitrate content of a crop like lettuce or spinach even grown without fertilizer - would already exceed such an RfD.

\section{Dietary iodine}

An important issue in environmental exposure to NIS inhibitors is the modulation of inhibition by dietary iodine. The model of competitive inhibition developed by Tonacchera et al. (9) predicts that thyroidal $\mathrm{I}^{-}$uptake is approximately proportional to iodide nutrition for any fixed underlying goitrogen load. Unfortunately, little or no data are available on the daily-required dose of dietary $\mathrm{I}^{-}$to withstand inhibition of NIS $\mathrm{I}^{-}$uptake by perchlorate, nitrate and thiocyanate present in drinking water and food. The model of Tonacchera et al. does not predict the levels of dietary $\mathrm{I}^{-}$and goitrogen load at which effects on thyroid economy will occur (9). In their key article, Greer et al. mention a separate report on the evaluation of the extent to which population variability in the magnitude of the response to perchlorate is related to iodine nutrition (14), but these data have not been published yet. Dr Goodman, co-author, stated that "iodine nutrition was not controlled and varied widely (several-fold) within individual subjects during the course of the study and even more widely (an order of magnitude) among subjects at the beginning of the study" (48). Braverman and colleagues suggest that the thyroid may be concentrating less of the dietary iodide during intermittent, high perchlorate exposure in employees of an ammonium perchlorate plant (17). Either way, iodine supplementation should be given to any person showing iodine deficiency, irrespective of whether there is significant exposure to environmental perchlorate, nitrate, thiocyanate or foods that naturally contain these anti-thyroid compounds or their precursors. Public health measures should also include mandatory adequate $\mathrm{I}^{-}$intake during pregnancy. Several other authors share this opinion $(14,24,34$, 49). The recommended daily iodine intake during pregnancy from the WHO/UNICEF/ICCIDD (2001) is $200 \mu \mathrm{g}$, while the US Institute of Medicine even suggests a recommended dietary allowance during pregnancy of $220 \mu \mathrm{g}$. A recent - though small - American study of Pearce and colleagues revealed that of 100 pregnant women in the Boston area (with the most strict proposed RfD for perchlorate), almost half (49\%) had iodine levels below the recommended dietary allowance and 9\% were even iodine deficient (50). In Europe, harbouring mild iodine deficiency in nearly two-thirds of the population of Western and Central Europe, adequate iodine supply for pregnant women and women planning a pregnancy is even more important $(49,51)$.

\section{Conclusions}

Considering the lack of sufficient information about the effects of perchlorate in sensitive populations such as foetuses, neonates and pregnant women, the recommendation of the NAS to define an NOEL as a (non-classic) departure point for perchlorate risk assessment seems to be defensible. On the other hand, the UF for the intraspecies variability suggested by the NAS (a full factor of 10) and in particular, the additional safety margins posed by some states, is probably overstating the health effects of perchlorate for several reasons; not only the POD is already an NOEL, but also other more prevalent NIS competitors such as nitrate 
and thiocyanate are not acknowledged, while the effect of perchlorate cannot be seen separately from the effects of these anions. Taking into account their individual $\mathrm{I}^{-}$ uptake inhibition potential at the level of NIS, which can be considered as robust since several studies agree on the perchlorate equivalence ratios, our calculations show that perchlorate accounts for less than $10 \%$ of possible thyroidal effects resulting from the exposure from drinking water; in food, its share is even negligible. The enormous discrepancy between the safe NOELbased RfD for perchlorate (in the context of iodine uptake inhibition) and the disproportionately high legally binding - LOEL-based RfD for nitrate (in the context of acquired methaemoglobinaemia) is not logical, and measures should be taken accordingly. Due to heterogeneity at several levels (inclusion of prevalent NIS inhibitors, type of exposure, populations exposed and measures of exposure) a meta-analysis of available human data - if at all possible - would probably not reveal new conclusions, underlining the need for scientific evidence from carefully designed human clinical studies evaluating the effects of nitrate and thiocyanate (along with dietary iodine) on $\mathrm{I}^{-}$ uptake inhibition, in order to determine RfDs for all prevalent NIS inhibitors in drinking water and food. Moreover, further animal studies are needed, investigating not only thyroidal, but also neurodevelopmental endpoints in circumstances of controlled intake of iodine, perchlorate, nitrate and thiocyanate.

\section{References}

1 Dai G, Levy O \& Carrasco N. Cloning and characterization of the thyroid iodide transporter. Nature 1996379 458-460.

2 Crooks J \& Wayne EJ. A comparison of potassium perchlorate, methylthiouracil, and carbimazole in the treatment of thyrotoxicosis. Lancet 19601 401-404.

3 Godley AF \& Stanbury JB. Preliminary experience in the treatment of hyperthyroidism with potassium perchlorate. Journal of Clinical Endocrinology and Metabolism 195414 70-78.

4 NRC (National Research Council). Health Implications of Perchlorate Ingestion. Washington DC: National Academies Press, 2005.

5 Eskandari S, Loo DD, Dai G, Levy O, Wright M \& Carrasco N. Thyroid $\mathrm{Na}^{+} / \mathrm{I}^{-}$symporter: mechanism, stoichiometry, and specificity. Journal of Biological Chemistry 1997272 2723027238.

6 Yoshida A, Sasaki N, Mori A, Taniguchi S, Mitani Y, Ueta Y, Hattori K, Sato R, Hisatome I, Mori T, Shigeamasa C \& Kosugi S. Different electrophysiological character of $\mathrm{I}^{-}, \mathrm{ClO}_{4}^{-}$, and $\mathrm{SCN}^{-}$in the transport by $\mathrm{Na}^{+} / \mathrm{I}^{-}$symporter. Biochemical and Biophysical Research Communications 1997231 731-734.

7 Yoshida A, Sasaki N, Mori A, Taniguchi S, Ueta Y, Hattori K, Tanaka Y, Igawa O, Tsuboi M, Sugawa H, Sato R, Hisatome I, Shigemasa C, Grollman EF \& Kosugi S. Differences in the electrophysiological response to $\mathrm{I}^{-}$and the inhibitory anions $\mathrm{SCN}^{-}$and $\mathrm{ClO}_{4}^{-}$, studied in FRTL-5 cells. Biochimica et Biophysica Acta $19981414231-237$.

8 Van Sande J, Massart C, Beauwens R, Schoutens A, Costagliola S, Dumont JE \& Wolff J. Anion selectivity by the sodium iodide symporter. Endocrinology $2003144247-252$.

9 Tonacchera M, Pinchera A, Dimida A, Ferrarini E, Agretti P, Vitti P, Santini F, Crump K \& Gibbs J. Relative potencies and additivity of perchlorate, thiocyanate, nitrate, and iodide on the inhibition of radioactive iodide uptake by the human sodium iodide symporter. Thyroid 200414 1012-1019.

10 Wyngaarden JB, Stanbury JB \& Rapp B. The effect of iodide, perchlorate, thiocyanate and nitrate administration upon the iodide concentrating mechanism of the rat thyroid. Endocrinology $195352568-574$.

11 Alexander WD \& Wolff J. Thyroidal iodide transport VIII, Relation between transport goitrogenic and antigoitrogenic properties of certain anions. Endocrinology 199678 581-590.

12 Greer MA, Stott AK \& Milne KA. Effect of thiocyanate, perchlorate and other anions on thyroidal iodine metabolism. Endocrinology $196679237-247$.

13 Krynitsky AJ, Niemann RA \& Nortrup DA. Determination of perchlorate anion in foods by ion chromatography-tandem mass spectrometry. Analytical Chemistry 200476 5518-5522.

14 Greer MA, Goodman G, Pleus RC \& Greer SE. Health effects assessment for environmental perchlorate contamination: the dose response for inhibition of thyroidal radioiodine uptake in humans. Environmental Health Perspectives 2002110 927-937.

15 Lawrence JE, Lamm SH, Pino S, Richman K \& Braverman LE. The effect of short-term low-dose perchlorate on various aspects of thyroid function. Thyroid $200010659-663$.

16 Lamm SH, Braverman LE, Li FX, Richman K, Pino S \& Howearth G. Thyroid health status of ammonium perchlorate workers: a crosssectional occupational health study. Journal of Occupational and Environmental Medicine 199941 248-260.

17 Braverman LE, He XM, Pino S, Cross M, Magnani B, Lamm SH, Kruse MB, Engel A, Crump KS \& Gibbs JP. The effect of perchlorate, thiocyanate, and nitrate on thyroid function in workers exposed to perchlorate long-term. Journal of Clinical Endocrinology and Metabolism 200590 700-706.

18 Crump KS \& Gibbs JP. Benchmark calculations for perchlorate from three human cohorts. Environmental Health Perspectives 2005 113 1001-1008.

19 Zoeller RT \& Rovert J. Timing of thyroid hormone action in the developing brain: clinical observations and experimental findings. Journal of Neuroendocrinology 200416 809-818.

20 Kreisner E, Schermann L, Camargo-Neto F \& Gross JL. Predictors of intellectual outcome in a cohort of Brazilian children with congenital hypothyroidism. Clinical Endocrinology (Oxford) 2004 $60250-255$.

21 Haddow JE, Palomaki GE, Allan WC, Williams JR, Knight GJ, Gagnon J, O'Heir CE, Mitchell ML, Hermos RJ, Waisbren SE, Faix ID \& Klein RZ. Maternal thyroid deficiency during pregnancy and subsequent neuropsychological development of the child. New England Journal of Medicine 1999 341 549-555.

22 Pop VJ, Brouwers EJ, Vader HL, Vulsma T, van Baar AL \& de Vijlder JJ. Maternal hypothyroxinemia during early pregnancy and subsequent child development: A 3 year follow-up study. Clinical Endocrinology $200359282-288$.

23 Vermiglio F, LoPresti VP, Moleti M, Sidoti M, Tortorella G, Scaffidi G, Castagna MG, Mattina F, Violi MA, Crisa A, Artermisia A \& Trimarchi F. Attention deficit and hyperactivity disorders in the offspring of mothers exposed to mild-moderate iodine deficiency: a possible novel iodine deficiency disorder in developed countries. Journal of Clinical Endocrinology and Metabolism 200489 6054-6060.

24 Morreale de Escobar G, Obregon MJ \& Escobar del Rey F. Role of thyroid hormone during early brain development. European Journal of Endocrinology 2004151 (Suppl. 3) U25-U37.

25 Soldin OP, Braverman LE \& Lamm SH. Perchlorate clinical pharmacology and human health: a review. Therapeutic Drug Monitoring 200123 316-331.

26 Li FX, Byrd DM, Deyhle GM, Sesser DE, Skeels MR, Katkowsky SR \& Lamm SH. Neonatal thyroid-stimulating hormone level and perchlorate in drinking water. Teratology 200062 429-431.

27 Li Z, Li FX, Byrd D, Deyhle GM, Sesser DE, Skeels MR \& Lamm $\mathrm{SH}$. Neonatal thyroxine level and perchlorate in drinking water. Journal of Occupational and Environmental Medicine 2000 42 200-205. 
28 Chang S, Crothers C, Lai S \& Lamm S. Pediatric neurobehavioral diseases in Nevada counties with respect to perchlorate in drinking water: an ecological inquiry. Birth Defects Research. Part A, Clinical and Molecular Teratology 200367 886-892.

29 Clewell RA, Merrill EA, Yu KO, Mahle DA, Sterner TR, Mattie DR, Robinson PJ, Fisher JW \& Gearhart JM. Predicting neonatal perchlorate dose and inhibition of iodide uptake in the rat during lactation using physiologically-based pharmacokinetic modeling. Toxicological Sciences $2003 \mathbf{7 4} 416-436$.

30 Crump C, Michaud P, Téllez R, Reyes C, Gonzalez G, Montgomery EL, Crump KS, Lobo G, Becerra C \& Gibbs JP. Does perchlorate in drinking water affect thyroid function in newborns or schoolage children? Journal of Occupational and Environmental Medicine 2000 42 603-612.

31 Strawson J, Zhao Q \& Dourson M. Reference dose for perchlorate based on thyroid hormone change in pregnant women as the critical effect. Regulatory Toxicology and Pharmacology 200439 44-65.

32 Téllez Téllez R, Michaud Chacon P, Reyes Abarca C, Blount B, Van Landingham C, Crump K \& Gibbs J. Chronic environmental exposure to perchlorate through drinking water and thyroid function during pregnancy and the neonatal period. Thyroid 2005 15 963-975.

33 Ginsberg G \& Rice D. The NAS perchlorate review: questions remain about the perchlorate RfD. Environmental Health Perspectives $20051131117-1119$.

34 Hershman JM. Perchlorate and thyroid function: what are the environmental issues? Thyroid 200515 427-431.

35 Muramoto J. Comparison of nitrate content in leafy vegetables from organic and conventional farms in California. Center for Agroecology and Sustainable Food Systems, University of California, Santa Cruz. June 1999.

36 Tajtakova M, Semanova Z, Tomkova Z, Szökeova E, Majoros J, Radikova Z, Sebökova E, Klimes I \& Langer P. Increased thyroid volume and frequency of thyroid disorders signs in schoolchildren from nitrate polluted area. Chemosphere $2006 \mathbf{6 2} 559-564$.

37 van Maanen JM, van Dijk A, Mulder K, de Baets MH, Menheere PC, van der Heide D, Mertens PL \& Kleinjans DC. Consumption of drinking water with high nitrate levels causes hypertrophy of the thyroid. Toxicology Letters 199472 365-374.

38 Bruce GM, Peterson MK \& Pleus RC. Comparative contribution of perchlorate and anti-thyroid agents in American diets to iodide uptake inhibition. Paper presented at the $32^{\text {nd }}$ Propellant Development \& Characterization Subcommittee and $21^{\text {st }}$ Safety \& Environmental Protection Subcommittee Joint Meeting, Seattle, WA, 29 July 2004.

39 Dorea JG. Maternal thiocyanate and thyroid status during breastfeeding. Journal of American College of Nutrition 200423 97-101.
40 Delanghe F, Itebeke F \& Ermans A. Nutritional factors involved in the goitrogenic action of cassava, pp. 1-25, Ottawa: International Development Research Centre, 1982.

41 Brauer VFH, Below H, Kramer A, Führer D \& Paschke R. The role of thiocyanate in the etiology of goiter in an industrial metropolitan area. European Journal of Endocrinology $2006 \mathbf{1 5 4}$ 229-235.

42 van Middlesworth L. Potential metabolic significance of blood thiocyanate. Endocrinologia Experimentalis 198620 17-22.

43 Laurbergh P, Nohr S, Pedersen K \& Fugisang E. Iodine nutrition in breast-fed infants is impaired by maternal smoking. Journal of Clinical Endocrinology and Metabolism 200489 181-187.

44 Capuco AV, Rice CP, Baldwin VI, Bannerman DD, Paape MJ, Hare WR, Kauf ACW, McCarty GW, Hapeman CJ, Sadeghi AM, Starr JL, McConnell LL \& Van Tassell CP. Fate of dietary perchlorate in lactating dairy cows: relevance to animal health and levels in the milk supply. Proceedings of the National Academy of Sciences 2005 102 16152-16157.

45 WHO/EOS/98.1 Guidelines for drinking water quality. 2nd edn. Addendum to Volume 2: Health Criteria and Other Supporting Information, 1998

46 Commission of The European Communities Scientific Committee for Food. Opinion on Nitrate and Nitrite expressed on 22 September 1995. Annex 4 to Document III/5611/95 1995.

47 Sanchez C, Krieger RI, Khandaker N, Moore RC, Holts KC \& Neidel LL. Accumulation and perchlorate exposure potential of lettuce produced in the lower Colorado River region. Journal of Agricultural and Food Chemistry 200553 5479-5486.

48 Goodman G. The dependence of thyroidal iodide uptake on perchlorate dose and iodine nutrition: modelling the clinical exposure data. Paper presented at the Society of Risk Analysis Annual Meeting, December 8-11 2002, URL source http://www. riskworld.com/Abstract/AB02ME01.HTM

49 Glinoer D. The regulation of thyroid function during normal pregnancy: importance of the iodine nutrition status. Best Practice and Research Clinical Endocrinology and Metabolism 200418 133-152.

50 Pearce E, Basrafshan E, He X, Pino S \& Braverman L. Dietary iodine in pregnant women from the Boston, Massachusetts area (Letter). Thyroid 200414 327-328.

51 Zimmerman M \& Delanghe F. Iodine supplementation of pregnant women in Europe: a review and recommendations. European Journal of Clinical Nutrition 200458 979-984.

Received 13 February 2006

Accepted 28 April 2006 